\title{
Characteristics of individuals receiving disability benefits in the Netherlands and predictors of leaving the disability benefit scheme: a retrospective cohort study with five-year follow-up
}

\author{
Ilse Louwerse $\mathrm{e}^{1,2,3^{*}}$ (D), Maaike A. Huysmans ${ }^{1,3}$, H. Jolanda van Rijssen ${ }^{1,2}$, Allard J. van der Beek ${ }^{1,3}$
} and Johannes R. Anema ${ }^{1,3}$

\begin{abstract}
Background: Today, work disability is one of the greatest social and labour market challenges for policy makers in most OECD countries, where on average, about $6 \%$ of the working-age population relies on disability benefits. Understanding of factors associated with long-term work disability may be helpful to identify groups of individuals at risk for disability benefit entitlement or continuing eligibility, and to develop effective interventions for these groups. The purpose of this study is to provide insight into the main diagnoses of workers who qualify for disability benefits and how these diagnoses differ in age, gender and education. Using a five-year follow-up, we examined the duration of disability benefits and how durations differ among individuals with various characteristics.

Methods: We performed a cohort study of 31,733 individuals receiving disability benefits from the Dutch Social Security Institute (SSI) with a five-year follow-up. Data were collected from SSI databases. Information about disorders was assessed by an insurance physician upon benefit application. These data were used to test for significant relationships among socio-demographics, main diagnoses and comorbidity, and disability benefit entitlement and continuing eligibility.

Results: Mental disorders were the most frequent diagnosis for individuals claiming work disability. Diagnoses differed among age groups and education categories. Mental disorders were the main diagnosis for work disability for younger and more highly educated individuals, and physical disorders (generally musculoskeletal, cardiovascular and cancer) were the main diagnosis for older and less educated individuals. In $82 \%$ of the claims, the duration of disability benefit was five years or more after approval. Outflow was lowest for individuals with (multiple) mental disorders and those with comorbidity of mental and physical disorders, and highest for individuals with (multiple) physical disorders.
\end{abstract}

Conclusions: The main diagnosis for persons entitled to disability benefits was mental health problems, especially for young women. In a five-year follow-up, claim duration for disability benefits was long lasting for most claimants.

Keywords: Disability benefit entitlement, Diagnosis, Mental disorders, Comorbidity, Continuing eligibility

\footnotetext{
* Correspondence: i.louwerse@vumc.nl

'Department of Public and Occupational Health, Amsterdam Public Health Research Institute, VU University Medical Center, Van der Boechorststraat 7, 1081, BT, Amsterdam, The Netherlands

2Dutch Institute of Employee Benefit Schemes (UM), Amsterdam, The Netherlands

Full list of author information is available at the end of the article
} 


\section{Background}

Today, work disability is one of the greatest social and labour market challenges for policy makers in most OECD countries [1]. On average, about $6 \%$ of the working-age population relies on disability benefits. Public spending on these benefits has become a serious burden. In the Netherlands, spending on disability benefits has risen to $4 \%$ of the gross domestic product. Moreover, once a disability benefit has been approved, the probability of returning to work is low [1]. Long-term unemployment or occupational inactivity is bad for an individual's health, especially those with mental health conditions, and returning to work is generally associated with health improvement [2-4]. Thus, prevention of work disability and support for returning to work are in the interest of individuals and society as a whole.

Dutch social security legislation allows workers to apply for a disability benefit after two years of sick leave (see Table 1) [5]. Disability benefits can be approved for a disease or handicap due to either social (i.e. nonoccupational) or occupational causes.

Return-to-work patterns and the effectiveness of interventions aimed at a return to work differ across individuals and their specific characteristics and health conditions [6, 7]. In Sweden, the majority of psychiatric outpatients with depression were female, less than 44 years, and had completed more than 9 years of compulsory education [8]. Moreover, the duration of mental health-related disability was influenced by socio-demographic factors such as age and education, and clinical factors such as comorbidity $[9,10]$. A Dutch study among cancer survivors following 2 years of sick leave concluded that among other factors, higher education, physical limitations and low self-reported work ability were associated with an increased risk for work disability [11]. For other physical disorders, such as lower back pain and major limb trauma, older age, low education level and smoking were significant predictors for long-term work disability $[12,13]$.

Whereas most studies about individuals at risk for longterm disability benefits and factors affecting return to work focus on a specific diagnosis, an overview of all

Table 1 Disability benefits in the Netherlands

In the Netherlands, disability benefits are assessed by the Dutch Social Security Institute (SSI). After two years of sick leave, individuals can apply for a disability benefit under the Dutch Work and Income Act (WIA). A medical disability assessment (i.e. diagnoses and functional abilities) is conducted by an insurance physician (IP) who is employed by the SSI. Depending on the functional abilities listed in the IP's report, there may also be an assessment by a labour expert who calculates the loss of former wages. A disability benefit is granted if loss of income exceeds 35\% of former wages. Disability benefits can be approved for a disease or handicap due to either social (i.e. non-occupational) or occupational causes.

Certain circumstances may change a person's continuing eligibility for disability benefits. A disability benefit ends if the SSI IP determines that the medical condition has improved substantially and the labour expert calculates that loss of income is less than 35\% of former wages. Other main causes are retirement and death. diagnoses is missing. Therefore, in the present study we included all individuals who had been granted a long-term disability benefit in the Netherlands. An overview of individual characteristics provides insight into the range of diagnoses and how they differ among age groups, gender and education. This approach can help to target specific at-risk groups and identify effective interventions to prevent long-term work disability. Therefore, the aim of this study was twofold. The first aim was to identify the most important diagnoses for which individuals claim an inability to work, and to examine how diagnoses differ among age groups, gender and educational levels. Second, using a five-year follow-up, we aimed to determine the duration of the disability benefit and how durations differed among individuals with various characteristics.

\section{Methods \\ Study population}

The study cohort included 31,733 subjects who had been granted a WIA disability benefit by the SSI between July 2010 and June 2011 after a medical disability assessment by an IP. Subjects in the study sample were assessed as having a full and permanent work disability, non-permanent but full work disability, or permanent and partial work disability. Individuals in the latter group had some work capacity and were possibly enrolled in a (part-time) job. Adults disabled since childhood were not included in the study sample since in the Netherlands they are not entitled to a WIA disability benefit (instead they can apply for a Disablement Assistance Act for Handicapped Young Persons disability benefit when they turn 18).

\section{Socio-demographics}

Socio-demographic data including gender, age and education are registered in the SSI database upon application for benefits. For further analysis, age was categorized into four groups: < 35, 35-44, 45-54 and 55+ years. Three education levels were defined based on the highest level of education completed; low (primary school, lower vocational education, lower secondary school), secondary (intermediate vocational education, upper secondary school), and high (upper vocational education, university). The educational level is usually registered during the labour expert's assessment. Since this assessment is not necessary when the IP assesses full and permanent work disability, the education level was missing for 4036 individuals in our study sample. We excluded these individuals from the analyses concerning the education level as we could not deduce any information about their educational level and were therefore not able to use the results.

\section{Disorders}

When applying for a disability benefit, the assessment of diagnoses and functional abilities is done by an IP who is 
employed by the SSI. The IP lists disorders according to the Dutch Classification of Occupational Health and Social Insurance (CAS). The CAS is based on the International Statistical Classification of Disease and Related Health Problems (ICD-10) diseases, a medical classification list from the World Health Organization [14]. The IP can list up to three disorders during the medical disability assessment. These diagnoses are divided into 14 categories, according to the ICD-10 classification, which we used in this study. .

\section{Comorbidity}

For this study we created a comorbidity classification scheme based on the CAS as established classification schemes did not fit our study data. CAS includes only information about the existence of disorders, and not about their severity. The IP lists in CAS the first (main) diagnosis for which an individual claims inability to work, and possibly a second and third diagnoses. The IP will only mention a second or third diagnoses if he or she believes that these result in important, additional functional disabilities. Therefore, in the present study, we considered all second and third diagnoses as comorbidity, independent of the disease categories of the ICD10 classification that the disorders belong to.

We defined comorbidity as two or three disorders being listed for an individual. To gain insight into the disorders present in cases of comorbidity, we divided the diagnostic categories into mental (mental disorders) and physical disorders (all remaining disorders). Possible conditions of comorbidity were multiple mental disorders, multiple physical disorders or a comorbidity of mental and physical disorders.

\section{Continuing eligibility for disability benefit}

We used a follow-up period of five years. For each individual in the study sample, we used SSI registration data to determine whether the benefit ended within one, three or five years after the date of approval (and if so, for what reason). During this five-year follow-up period there were no major changes in legislation or working processes that could have influenced our results.

\section{Statistical analysis}

Statistical analyses were performed in RStudio for Windows, version 0.99.902. The chi-square test for categorical variables was used to compare socio-demographic characteristics, disorders, comorbidity and outflow from disability benefits among various groups of individuals. Multinomial regression models were used to test for relationships between disorders, comorbidity and outflow from disability benefit respectively (dependent variable) and socio-demographic characteristics, disorders and comorbidity (independent variables) while taking confounding effects into account. The level of significance was set at $p<0.05$.

\section{Results}

\section{Characteristics of the study population}

The socio-demographic characteristics and disorders of the study population are summarized in Table 2 . To facilitate interpretation, all numbers were rounded to the nearest ten. The mean age was 46.8 years (SD, 10.6) and the number of men and women was approximately equal.

Table 3 shows the age categories and educational levels divided by gender. Women who qualified for disability benefits were on average younger $\left[\mathrm{x}^{2}(\mathrm{df}=3 ; n=31,733)=\right.$ 519.33, $p=0.000]$, and more highly educated $\left[\mathrm{X}^{2}(\mathrm{df}=2 ; n\right.$ $=27,697)=262.43, p=0.000]$ than men.

\section{Main diagnoses for work disability}

Table 2 shows the main disorders as listed by the IP for medical disability assessment. Mental disorders were most often mentioned, followed by musculoskeletal disorders, nervous system disorders, cancer and cardiovascular system disorders. The category "other" consisted of various classes of physical disorders that were listed less frequently (among others respiratory system, digestive system and genitourinary system disorders).

Table 2 Summary of socio-demographic characteristics and disorders

Study sample $\mathrm{n}=31,730$

n (\%)

\begin{tabular}{ll}
\hline Socio-demographics & \\
Gender & $15,650(49)$ \\
Male & $16,090(51)$ \\
Female & \\
Age category & $5210(16)$ \\
$\quad<35$ & $7060(22)$ \\
$35-44$ & $10,160(32)$ \\
$45-54$ & $9300(29)$ \\
$55+$ & \\
Educational level & $16,820(53)$ \\
Low & $7390(23)$ \\
Secondary & $3500(11)$ \\
High & $4040(13)$ \\
Unknown & \\
Disorders & \\
Main causes of work disability & $2510(8)$ \\
Cancer & $2790(9)$ \\
Cardiovascular & $10,870(34)$ \\
Mental & $8410(27)$ \\
Musculoskeletal & $2090(9)$ \\
Nervous system & $4260(13)$ \\
\hline Other &
\end{tabular}


Table 3 Age and educational level by gender

\begin{tabular}{|c|c|c|}
\hline & \multicolumn{2}{|l|}{$\begin{array}{l}\text { Gender } \\
\mathrm{n}(\%)\end{array}$} \\
\hline & Male & Female \\
\hline \multicolumn{3}{|l|}{ Age category } \\
\hline$<35$ & $2070(13)$ & $3140(20)$ \\
\hline $35-44$ & $3230(21)$ & $3830(24)$ \\
\hline $45-54$ & 4940 (32) & $5220(33)$ \\
\hline $55+$ & $5400(35)$ & $3890(24)$ \\
\hline \multicolumn{3}{|c|}{ Educational level } \\
\hline Low & $8860(57)$ & $7960(50)$ \\
\hline Secondary & $3290(21)$ & $4100(26)$ \\
\hline High & $1400(9)$ & $2100(13)$ \\
\hline Unknown & 2100 (13) & 1940 (12) \\
\hline
\end{tabular}

Table 4 shows that the main diagnosis for work disability differed significantly among age categories $\left[\mathrm{X}^{2}(\mathrm{df}=15 ; n=\right.$ $31,733)=3306.1, p=0.000$ ], with mental disorders as the main diagnosis for individuals younger than 55 years, and musculoskeletal disorders the main diagnosis for individuals 55 years and older. The differences in leading diagnoses between men and women were statistically significant but smaller $\left[\mathrm{X}^{2}(\mathrm{df}=5 ; \mathrm{n}=31,733)=541.15, p=0.000\right]$. Mental and musculoskeletal disorders were registered with approximately the same frequency for women and men. However, cancer was more often registered for women (mostly breast cancer) and cardiovascular disorders for men (mostly stroke, heart attack).

The leading diagnosis also differed for educational level $\left[\mathrm{X}^{2}(\mathrm{df}=10 ; n=27,697)=857.12, \mathrm{p}=0.000\right]$. Individuals who were more highly educated suffered more often from mental disorders, nervous system disorders and cancer, whereas individuals who were less educated suffered more often from musculoskeletal and cardiovascular disorders.

\section{Comorbidity}

More than half of the individuals in the study population (55.8\%) suffered from comorbidity. Table 5 shows that work disability due to comorbidity was mentioned as frequently for men as for women $\left[\chi^{2}(\mathrm{df}=1 ; n=31,733)=0.356, p=0.551\right]$, and more often for older $\left[\mathrm{x}^{2}(\mathrm{df}=3 ; \mathrm{n}=31,733)=92.866, p=\right.$ $0.000]$ and less educated individuals $\left[X^{2}(\mathrm{df}=2 ; n=27,697)=\right.$ 168.65, $p=0.000$ ]. Considering the main diagnoses for work disability $\left[\mathrm{x}^{2}(\mathrm{df}=5 ; \mathrm{n}=31,733)=765.29, p=0.000\right]$, individuals with cancer suffered least often from comorbidity and individuals with musculoskeletal disorders most often.

Figure 1 shows the (combination of types of) diagnoses registered by the IP during a medical disability assessment for each age category. For younger individuals, comorbidity was most often a combination of multiple mental disorders, and for older individuals it was most often a combination of multiple physical diagnoses (musculoskeletal, nervous or cardiovascular disorders).

\section{Continuing eligibility for disability benefits}

Of the individuals who had been granted a disability benefit in the study time frame, 964 individuals (3\%) left in the first year, 2607 (8\%) in the second and third year, and 2258 (7\%) in the fourth and fifth year. All other individuals $(25,907$; $82 \%)$ continued to receive disability benefits after five years. Outflow was caused by retirement (37\%), death (30\%), improvement of the medical condition (such that individuals could earn at least $65 \%$ of former wages [28\%]), or other reasons such as imprisonment or pregnancy (5\%).

Table 6 shows that the main reason for outflow in the first year was death, in the second and third year income loss lower than $35 \%$ of former wages earned, and in the fourth and fifth year retirement. Table 7 shows that the differences for gender $\left[\chi^{2}(\mathrm{df}=3 ; n=31,733)=37.549, p=\right.$ $0.000]$ and age categories $\left[\mathrm{x}^{2}(\mathrm{df}=9 ; \mathrm{n}=31,733)=2259.8, p\right.$ $=0.000]$ were statistically significant, but small. There was

Table 4 Main diagnosis by age, gender and educational level

\begin{tabular}{|c|c|c|c|c|c|c|}
\hline & \multicolumn{6}{|c|}{$\begin{array}{l}\text { Main diagnosis } \\
\mathrm{n}(\%)\end{array}$} \\
\hline & Mental & Musculoskeletal & Nervous system & Cardiovascular & Cancer & Other \\
\hline \multicolumn{7}{|l|}{ Gender } \\
\hline Male & $5160(33)$ & $4170(27)$ & $1460(9)$ & $1860(12)$ & $890(6)$ & $2110(13)$ \\
\hline Female & $5710(35)$ & $4240(26)$ & $1450(9)$ & $930(6)$ & $1620(10)$ & $2150(13)$ \\
\hline \multicolumn{7}{|l|}{ Age category } \\
\hline$<35$ & $2970(57)$ & $1000(19)$ & $460(9)$ & $80(1)$ & $120(2)$ & $590(11)$ \\
\hline $35-44$ & $3150(45)$ & $1690(24)$ & $670(10)$ & $320(5)$ & $360(5)$ & $860(12)$ \\
\hline $45-54$ & $3010(30)$ & $2910(29)$ & $950(9)$ & $1010(10)$ & $960(9)$ & $1340(13)$ \\
\hline $55+$ & $1740(19)$ & $2810(30)$ & $820(9)$ & $1380(15)$ & $1070(12)$ & $1470(16)$ \\
\hline \multicolumn{7}{|c|}{ Educational level } \\
\hline Low & $5350(32)$ & $5860(35)$ & $1210(7)$ & $1470(9)$ & $830(5)$ & $2100(12)$ \\
\hline Secondary & $2680(36)$ & $1820(25)$ & $750(10)$ & $610(8)$ & $470(6)$ & $1070(14)$ \\
\hline High & $1510(43)$ & $470(13)$ & $450(13)$ & $280(8)$ & $280(8)$ & $500(14)$ \\
\hline
\end{tabular}


Table 5 Comorbidity by age, gender, educational level and main diagnosis

\begin{tabular}{|c|c|c|}
\hline & $\begin{array}{l}\text { Comorbidity } \\
\mathrm{n}(\%)\end{array}$ & \\
\hline & Yes & No \\
\hline \multicolumn{3}{|l|}{ Gender } \\
\hline Male & $8700(56)$ & $6940(44)$ \\
\hline Female & $9010(56)$ & $7080(44)$ \\
\hline \multicolumn{3}{|l|}{ Age category } \\
\hline$<35$ & $2690(52)$ & $2520(48)$ \\
\hline $35-44$ & $3770(53)$ & $3290(47)$ \\
\hline $45-54$ & $5780(57)$ & $4390(43)$ \\
\hline $55+$ & $5470(59)$ & $3830(41)$ \\
\hline \multicolumn{3}{|l|}{ Educational level } \\
\hline Low & $10,240(61)$ & $6580(39)$ \\
\hline Secondary & $4060(55)$ & $3330(45)$ \\
\hline High & $1760(50)$ & $1730(50)$ \\
\hline \multicolumn{3}{|c|}{ Main diagnosis causing work disability } \\
\hline Cancer & $930(37)$ & $1580(63)$ \\
\hline Cardiovascular & $1640(59)$ & $1150(41)$ \\
\hline Mental & $6310(58)$ & $4560(42)$ \\
\hline Musculoskeletal & $5180(62)$ & $3230(38)$ \\
\hline Nervous system & $1190(41)$ & $1710(59)$ \\
\hline Other & $2460(58)$ & $1800(41)$ \\
\hline
\end{tabular}

no difference for education categories $\left[\mathrm{x}^{2} \quad(\mathrm{df}=6 ; n=\right.$ $27,697)=5.9007, p=0.434]$.

The outflow of disability benefits differed by class of the leading diagnoses for work disability $\left[\mathrm{X}^{2}(\mathrm{df}=15 ; n=31,733)\right.$ $=2148.4, p=0.000]$. In the first year, the outflow consisted mainly of individuals diagnosed with cancer who died within one year after their disability benefit was approved. After four and five years, more older individuals with musculoskeletal and cardiovascular disorders left because of retirement.
Continuing eligibility for disability benefits was highest for individuals with single or multiple mental disorders and individuals facing a comorbidity of mental and physical disorders, and lowest for individuals with single or multiple physical disorders $\left[\mathrm{X}^{2}(\mathrm{df}=15 ; \mathrm{n}=31,733)=653.9, p=0.000\right]$.

\section{Discussion \\ Main findings}

Disability diagnoses differed significantly among age groups and education categories; mental disorders were the main diagnosis for work disability for younger and more highly educated individuals, and physical disorders (mainly musculoskeletal, cardiovascular and cancer) for older and less educated individuals. The differences between men and women were small.

Multiple diagnoses were registered for more than half of the population. Older and less educated individuals suffered relatively often from comorbidity.

In the five-year follow-up, the continuation of disability benefits for five years or more after approval was high. Only $18 \%$ of the individuals in our study sample discontinued their disability benefits in the five-year follow-up period. Continuing eligibility for disability benefit was highest for individuals with (multiple) mental disorders and those with a comorbidity of mental and physical disorders, and lowest for individuals with (multiple) physical disorders.

\section{Interpretation of findings and comparison with other studies}

The current finding that women who qualify for disability benefits are on average younger and more educated than men confirms previously reported findings. A reason for this difference in age of entry to disability benefits is the relatively low number of older women among the insured population [15]. This is most likely because a few decades ago many women did not continue paid work after giving birth. More recently, the proportion of women aged 50-64 years in the

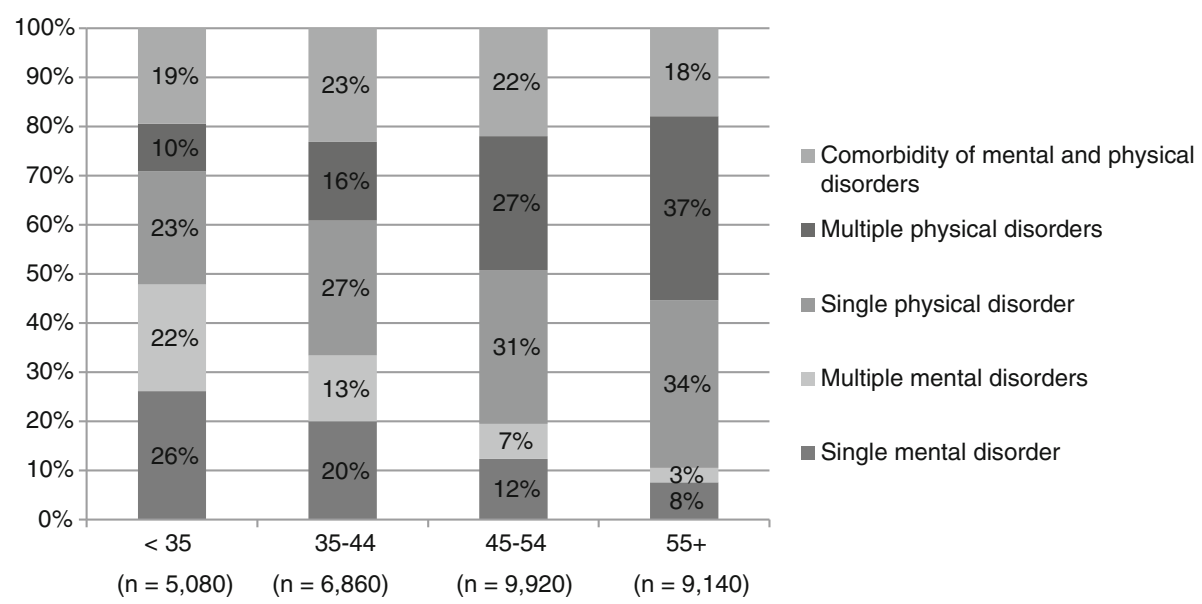

Fig. 1 Comorbidity for individuals of various age groups 
Table 6 Timing and reason for outflow of disability benefit

\begin{tabular}{|c|c|c|c|c|c|}
\hline & \multicolumn{4}{|c|}{$\begin{array}{l}\text { Reason for outflow of disability benefit } \\
\mathrm{n}(\%)\end{array}$} & \multirow[b]{2}{*}{ Total } \\
\hline & Retirement & Death & Income loss $<35 \%$ & Other & \\
\hline \multicolumn{6}{|c|}{ Outflow of disability benefit } \\
\hline 1st year & $200(21)$ & $490(52)$ & $170(18)$ & $100(10)$ & $960(100)$ \\
\hline 2nd or 3rd year & $790(30)$ & $750(29)$ & $930(36)$ & $140(5)$ & $2610(100$ \\
\hline 4th or 5th year & $1140(50)$ & $510(22)$ & $540(24)$ & $80(3)$ & $2260(100$ \\
\hline
\end{tabular}

workforce has increased, and is still increasing such that the employment gap between men and women is becoming smaller $[16,17]$.

We found that mental disorders were the main diagnosis for work disability. This is in line with the finding that mental disorders are the leading cause of sickness absence and work disability in OECD countries [18]. Research shows that mental health impairments have increased over the past years. This could be explained by the changing content of communication and social networks, and the changed and increased job demands in the workplace [19, 20]. All these factors make it increasingly difficult for workers with mental health problems to return to work.
Our finding that younger individuals in particular suffer from mental disorders corresponds with the finding that younger generations are at increased risk for mental health problems $[1,21]$. Two major explanations are changes in the workplace that have increased the prevalence of workrelated stress, and the changing content of communication and social networks. Our finding is a problem because work absence due to mental illness is often long lasting. In the Netherlands, the median duration of absence due to mental illness has increased. The probability of resuming work decreases with the increasing duration of absence due to illness [22]. Conversely, the prevalence of musculoskeletal disorders as the main diagnosis for work disability is higher for older

Table 7 Outflow of disability benefits by age, gender, education, main diagnosis and comorbidity

\begin{tabular}{|c|c|c|c|c|}
\hline & \multicolumn{4}{|c|}{$\begin{array}{l}\text { Outflow of disability benefit } \\
\text { n (\%) }\end{array}$} \\
\hline & 1st year & 2nd or 3rd year & 4 th or 5 th year & Continuing eligibility \\
\hline \multicolumn{5}{|l|}{ Gender } \\
\hline Male & $510(3)$ & $1330(8)$ & $1230(8)$ & $12,590(80)$ \\
\hline Female & $450(3)$ & $1280(8)$ & $1030(6)$ & $13,330(83)$ \\
\hline \multicolumn{5}{|l|}{ Age category } \\
\hline$<35$ & $110(2)$ & $370(7)$ & $200(4)$ & $4530(87)$ \\
\hline $35-44$ & $130(2)$ & $510(7)$ & $220(3)$ & $6200(88)$ \\
\hline $45-54$ & $230(2)$ & $560(5)$ & $380(4)$ & $9000(88)$ \\
\hline $55+$ & $490(5)$ & $1170(13)$ & $1450(16)$ & $6180(66)$ \\
\hline \multicolumn{5}{|l|}{ Education level } \\
\hline Low & $360(2)$ & $1300(8)$ & $1200(7)$ & $13,950(83)$ \\
\hline Secondary & $160(2)$ & $570(8)$ & $450(7)$ & $6150(83)$ \\
\hline High & $70(2)$ & $290(8)$ & $270(8)$ & $2860(82)$ \\
\hline \multicolumn{5}{|c|}{ Main diagnosis causing work disability } \\
\hline Mental & $160(1)$ & $670(6)$ & $540(5)$ & $9500(87)$ \\
\hline Musculoskeletal & $190(2)$ & $650(8)$ & $570(7)$ & $7000(83)$ \\
\hline Nervous system & $50(2)$ & $150(5)$ & $220(7)$ & $2490(86)$ \\
\hline Cardiovascular & $60(2)$ & $250(9)$ & $300(11)$ & $2180(78)$ \\
\hline Cancer & $370(15)$ & $490(19)$ & $250(10)$ & $1410(56)$ \\
\hline Other & $140(3)$ & $400(9)$ & $390(9)$ & $3330(78)$ \\
\hline \multicolumn{5}{|l|}{ Comorbidity } \\
\hline Single mental disorder & $80(2)$ & $310(7)$ & $220(5)$ & $4020(87)$ \\
\hline Multiple mental disorders & $30(1)$ & $160(5)$ & $130(4)$ & $2680(89)$ \\
\hline Single physical disorder & $490(5)$ & $940(10)$ & $770(8)$ & $7070(76)$ \\
\hline Multiple physical disorders & $250(3)$ & $740(10)$ & $710(9)$ & $6010(78)$ \\
\hline Mental and physical disorders & $100(2)$ & $410(6)$ & $390(6)$ & $5490(86)$ \\
\hline
\end{tabular}


individuals. An association between age and musculoskeletal disorders is generally found in several studies [23, 24].

Concerning the relationship between the main diagnoses for work disability and education, we found that individuals who were more highly educated suffered more often from mental disorders, nervous system disorders and cancer, and individuals who were less educated suffered more often from musculoskeletal and cardiovascular disorders. This may be due to differences in the type of jobs and workplaces for these two groups.

A considerable part of our study population (65\%) suffered from comorbidity. Research shows the importance of comorbidity as a predictor for long-term work disability [25]. Multiple physical symptoms have a generic negative influence on the effectiveness of treatment for symptoms of depression and anxiety in primary care [26].

The duration of disability benefits is longer for older workers, when the main diagnosis for work disability is a mental disorder and when comorbidity is present, and only related to gender and education to a limited extent. Similar findings can be found in the literature on prognostic factors for long-term disability due to mental disorders [27]. Of the individuals in the study population, $82 \%$ had continuing eligibility for their disability benefits five years after approval. An application for disability benefits can be requested after two years of sick leave. This means that individuals who qualify for disability benefits have already been sick for a long period of time and have severe disorders that may be more difficult to treat. In addition, in these two years, the system does not offer many incentives for individuals to return to work. Hence, (partial) recovery after two years of sick leave would be unexpected. This could explain the low outflow in the present cohort.

\section{Strengths and limitations of the study}

An important strength of this study is the large study sample. By covering the entire Dutch population applying for long-term disability benefits, with a one-year inflow period and a five-year follow-up period, our study population is highly inclusive. To our knowledge studies about individuals at risk for long-term disability benefits generally focus on one specific diagnosis, while we included all individuals who were granted a disability benefit in the Netherlands in the one-year inflow period. By doing this, we can give an overview of all diagnoses for which individuals claim work disability. In addition, in most studies in the field of work disability the follow-up period is only one or two years, while we were able to use a follow-up period of five years after approval of the benefit.

We performed a similar study with individuals who were granted a disability benefit in 2015 and the individual characteristics, main diagnoses for work disability and comorbidity numbers were similar to the ones in this study, thus confirming our results here. The figures on the socio-demographic characteristics of individuals receiving disability benefits are also consistent with SSI data [28].

A limitation of only testing for bivariate relationships is that it is not possible to control for confounding effects. Therefore, we have also performed three multinomial regression analyses (with main diagnosis for work disability, comorbidity and continuing eligibility for disability benefits respectively as the dependent variables). The results of these regression analyses can be found in Appendix A. They confirm the statistical bivariate relations that we found with the chi-square tests.

A study limitation is that data was not collected for research purposes, but rather registered by SSI employees for administration purposes. Although careful registration is important for internal processes, employees might not have been fully aware of the importance of complete and comprehensive administration and some records contained missing data. For that reason, we had to exclude 4036 individuals from our analyses concerning the education level as their values were missing. In this study, we considered only sociodemographic factors, main diagnosis, comorbidity and claim duration. However, there could be other factors (partly) explaining our findings.

\section{Practical implications}

This study provides insight into the socio-demographic factors and health complaints of individuals who qualify for disability benefits in the Netherlands and shows that continuing eligibility for disability benefits is high. This information can help identify specific at-risk groups when policies are aimed at decreasing the number of applications for disability benefits. The results of this study may be useful when policy makers investigate how to reduce long-term disability benefits. In this context, the main focus should be on individuals who leave for reasons other than retirement and death. Increased understanding of the characteristics of this group and how to support them in returning to work is needed. Conducting re-assessments, wherein the SSI would assess whether or not someone's health had improved enough so that their earning capacity had increased, is a possible way to motivate individuals to return to work.

\section{Conclusions}

This study provides an overview of the sociodemographic characteristics and diagnoses of individuals who have been granted a disability benefit, and examines the duration of their benefit. Therefore, it contributes to insight into the range of diagnoses and how they differ in age, gender and education. An understanding of factors associated with long-term work disability may be helpful to identify groups of individuals who are at risk for continuing eligibility for disability benefits and to develop effective interventions for these groups. 


\section{Appendix 1}

Table 8 Relation between main diagnosis for work disability and socio-demographic characteristics

\begin{tabular}{|c|c|c|c|c|c|c|}
\hline Main diagnosis ${ }^{\mathrm{a}}$ & Independent variables & Coefficient & Standard error & Z statistic & $p$-value & Relative risk ratio \\
\hline \multirow[t]{10}{*}{ Musculoskeletal } & Intercept & -2.484 & 0.074 & -33.47 & 0.000 & \\
\hline & Gender & & & & & \\
\hline & Male & 1.00 (ref) & & & & \\
\hline & Female & 0.095 & 0.031 & 3.10 & 0.002 & 1.10 \\
\hline & Age & 0.055 & 0.001 & 37.17 & 0.000 & 1.06 \\
\hline & Educational level & & & & & \\
\hline & Low & 1.00 (ref) & & & & \\
\hline & Secondary & -0.379 & 0.039 & -10.27 & 0.000 & 0.68 \\
\hline & High & -1.293 & 0.057 & -22.59 & 0.000 & 0.27 \\
\hline & Unknown & -1.820 & 0.072 & -25.41 & 0.000 & 0.16 \\
\hline \multirow[t]{10}{*}{ Nervous system } & Intercept & -3.135 & 0.104 & -30.15 & 0.000 & \\
\hline & Gender & & & & & \\
\hline & Male & 1.00 (ref) & & & & \\
\hline & Female & -0.018 & 0.043 & -0.43 & 0.666 & 0.98 \\
\hline & Age & 0.037 & 0.002 & 28.23 & 0.000 & 1.04 \\
\hline & Educational level & & & & & \\
\hline & Low & 1.00 (ref) & & & & \\
\hline & Secondary & 0.284 & 0.053 & 5.37 & 0.000 & 1.33 \\
\hline & High & 0.260 & 0.063 & 4.11 & 0.000 & 1.30 \\
\hline & Unknown & 0.447 & 0.062 & 7.21 & 0.000 & 1.56 \\
\hline \multirow[t]{10}{*}{ Cardiovascular system } & Intercept & -6.185 & 0.141 & -43.97 & 0.000 & \\
\hline & Gender & & & & & \\
\hline & Male & 1.00 (ref) & & & & \\
\hline & Female & -0.518 & 0.046 & -11.17 & 0.000 & 0.60 \\
\hline & Age & 0.106 & 0.003 & 40.37 & 0.000 & 1.11 \\
\hline & Educational level & & & & & \\
\hline & Low & 1.00 (ref) & & & & \\
\hline & Secondary & 0.014 & 0.056 & 0.25 & 0.805 & 1.01 \\
\hline & High & -0.395 & 0.074 & -5.33 & 0.000 & 0.67 \\
\hline & Unknown & -0.001 & 0.066 & -0.02 & 0.985 & 1.00 \\
\hline \multirow[t]{10}{*}{ Cancer } & Intercept & -6.615 & 0.144 & -45.87 & 0.000 & \\
\hline & Gender & & & & & \\
\hline & Male & 1.00 (ref) & & & & \\
\hline & Female & 0.775 & 0.049 & 15.92 & 0.000 & 2.17 \\
\hline & Age & 0.091 & 0.003 & 34.93 & 0.000 & 1.10 \\
\hline & Educational level & & & & & \\
\hline & Low & 1.00 (ref) & & & & \\
\hline & Secondary & 0.257 & 0.064 & 4.00 & 0.000 & 1.29 \\
\hline & High & 0.096 & 0.077 & 1.28 & 0.200 & 1.10 \\
\hline & Unknown & 1.396 & 0.059 & 23.52 & 0.000 & 4.04 \\
\hline
\end{tabular}


Table 8 Relation between main diagnosis for work disability and socio-demographic characteristics (Continued)

\begin{tabular}{|c|c|c|c|c|c|c|}
\hline Main diagnosis ${ }^{a}$ & Independent variables & Coefficient & Standard error & Z statistic & $p$-value & Relative risk ratio \\
\hline \multirow[t]{10}{*}{ Other } & Intercept & -3.303 & 0.093 & -35.48 & 0.000 & \\
\hline & Gender & & & & & \\
\hline & Male & 1.00 (ref) & & & & \\
\hline & Female & 0.061 & 0.037 & 1.63 & 0.103 & 1.06 \\
\hline & Age & 0.051 & 0.002 & 28.23 & 0.000 & 1.05 \\
\hline & Educational level & & & & & \\
\hline & Low & 1.00 (ref) & & & & \\
\hline & Secondary & 0.107 & 0.045 & 2.36 & 0.018 & 1.11 \\
\hline & High & -0.197 & 0.059 & -3.36 & 0.000 & 0.82 \\
\hline & Unknown & 0.035 & 0.057 & 0.61 & 0.543 & 1.04 \\
\hline
\end{tabular}

${ }^{a}$ Reference category is mental disorders

Table 9 Relation between comorbidity and socio-demographic characteristics and main diagnosis for work disability

\begin{tabular}{|c|c|c|c|c|c|c|}
\hline Comorbidity $^{a}$ & Independent variables & Coefficient & Standard error & Z statistic & $p$-value & Relative risk ratio \\
\hline \multirow{17}{*}{$\begin{array}{l}\text { Multiple mental, multiple physical or comorbidity } \\
\text { of mental and physical disorders }\end{array}$} & Intercept & -0.231 & 0.057 & -4.08 & 0.000 & \\
\hline & \multicolumn{6}{|l|}{ Gender } \\
\hline & Male & 1.00 (ref) & & & & \\
\hline & Female & 0.103 & 0.024 & 4.37 & 0.000 & 0.80 \\
\hline & Age & 0.016 & 0.001 & 13.99 & 0.000 & 1.11 \\
\hline & \multicolumn{6}{|l|}{ Educational level } \\
\hline & Low & 1.00 (ref) & & & & \\
\hline & Secondary & -0.193 & 0.029 & -6.71 & 0.000 & 0.82 \\
\hline & High & -0.382 & 0.038 & -9.96 & 0.000 & 0.68 \\
\hline & Unknown & -0.670 & 0.037 & -17.88 & 0.000 & 0.51 \\
\hline & \multicolumn{6}{|l|}{ Main diagnosis } \\
\hline & Mental & 1.00 (ref) & & & & \\
\hline & Musculoskeletal & -0.044 & 0.031 & -1.40 & 0.160 & 0.96 \\
\hline & Nervous system & -0.723 & 0.043 & -16.73 & 0.000 & 0.49 \\
\hline & Cardiovascular & -0.121 & 0.045 & -2.66 & 0.008 & 0.89 \\
\hline & Cancer & -0.887 & 0.048 & -18.41 & 0.000 & 0.41 \\
\hline & Other & -0.095 & 0.038 & -2.53 & 0.013 & 0.91 \\
\hline
\end{tabular}

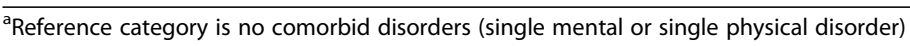


Table 10 Relation between continuing eligibility for disability benefit and socio-demographic characteristics, main diagnosis for work disability and comorbidity

\begin{tabular}{|c|c|c|c|c|c|c|}
\hline Outflow of disability benefit ${ }^{a}$ & Independent variables & Coefficient & Standard error & Z statistic & $p$-value & Relative risk ratio \\
\hline \multirow[t]{23}{*}{ Outflow in 1st year } & Intercept & -5.934 & 0.230 & -25.78 & 0.000 & \\
\hline & \multicolumn{6}{|l|}{ Gender } \\
\hline & Male & 1.00 (ref) & & & & \\
\hline & Female & -0.255 & 0.070 & -3.64 & 0.000 & 0.78 \\
\hline & Age & 0.042 & 0.004 & 10.36 & 0.000 & 1.04 \\
\hline & \multicolumn{6}{|l|}{ Educational level } \\
\hline & Low & 1.00 (ref) & & & & \\
\hline & Secondary & 0.057 & 0.099 & 0.58 & 0.564 & 1.06 \\
\hline & High & -0.024 & 0.133 & -0.18 & 0.860 & 0.98 \\
\hline & Unknown & 1.033 & 0.087 & 11.84 & 0.000 & 2.81 \\
\hline & \multicolumn{6}{|l|}{ Main diagnosis } \\
\hline & Mental & 1.00 (ref) & & & & \\
\hline & Musculoskeletal & -0.347 & 0.214 & -1.62 & 0.105 & 0.71 \\
\hline & Nervous system & -0.925 & 0.249 & -3.71 & 0.000 & 0.40 \\
\hline & Cardiovascular & -0.761 & 0.241 & -3.15 & 0.002 & 0.47 \\
\hline & Cancer & 1.351 & 0.213 & 6.33 & 0.000 & 3.86 \\
\hline & Other & -0.079 & 0.221 & -0.17 & 0.864 & 0.96 \\
\hline & \multicolumn{6}{|l|}{ Comorbidity } \\
\hline & Single mental disorder & 1.00 (ref) & & & & \\
\hline & Multiple mental disorders & -0.302 & 0.211 & -1.43 & 0.153 & 0.74 \\
\hline & Single physical disorder & 0.876 & 0.242 & 3.62 & 0.000 & 2.10 \\
\hline & Multiple physical disorders & 0.617 & 0.246 & 2.51 & 0.012 & 1.85 \\
\hline & Mental and physical & -0.066 & 0.184 & -0.36 & 0.721 & 0.94 \\
\hline \multirow[t]{20}{*}{ Outflow in 2nd or 3rd year } & Intercept & -4.060 & 0.126 & -32.15 & 0.000 & \\
\hline & \multicolumn{6}{|l|}{ Gender } \\
\hline & Male & 1.00 (ref) & & & & \\
\hline & Female & -0.079 & 0.043 & -1.83 & 0.067 & 0.92 \\
\hline & Age & 0.034 & 0.002 & 14.57 & 0.000 & 1.03 \\
\hline & \multicolumn{6}{|l|}{ Educational level } \\
\hline & Low & 1.00 (ref) & & & & \\
\hline & Secondary & 0.068 & 0.054 & 1.27 & 0.203 & 1.07 \\
\hline & High & 0.088 & 0.070 & 1.25 & 0.210 & 1.09 \\
\hline & Unknown & 0.204 & 0.063 & 3.21 & 0.001 & 1.22 \\
\hline & \multicolumn{6}{|l|}{ Main diagnosis } \\
\hline & Mental & 1.00 (ref) & & & & \\
\hline & Musculoskeletal & -0.114 & 0.108 & -1.62 & 0.293 & 0.89 \\
\hline & Nervous system & -0.572 & 0.133 & -4.32 & 0.000 & 0.56 \\
\hline & Cardiovascular & -0.098 & 0.122 & -0.81 & 0.421 & 0.91 \\
\hline & Cancer & 1.029 & 0.116 & 8.85 & 0.000 & 2.80 \\
\hline & Other & 0.184 & 0.115 & 1.60 & 0.110 & 1.20 \\
\hline & \multicolumn{6}{|l|}{ Comorbidity } \\
\hline & Single mental disorder & 1.00 (ref) & & & & \\
\hline & Multiple mental disorders & -0.133 & 0.100 & -1.32 & 0.186 & 0.88 \\
\hline
\end{tabular}


Table 10 Relation between continuing eligibility for disability benefit and socio-demographic characteristics, main diagnosis for work disability and comorbidity (Continued)

\begin{tabular}{|c|c|c|c|c|c|c|}
\hline Outflow of disability benefit ${ }^{a}$ & Independent variables & Coefficient & Standard error & Z statistic & $p$-value & Relative risk ratio \\
\hline & Single physical disorder & 0.238 & 0.125 & 1.90 & 0.058 & 1.27 \\
\hline & Multiple physical disorders & 0.171 & 0.127 & 1.35 & 0.178 & 1.19 \\
\hline & Mental and physical & -0.180 & 0.095 & -1.89 & 0.880 & 0.84 \\
\hline \multirow[t]{23}{*}{ Outflow in 4th or 5th year } & Intercept & -6.879 & 0.170 & -40.54 & 0.000 & \\
\hline & Gender & & & & & \\
\hline & Male & 1.00 (ref) & & & & \\
\hline & Female & -0.048 & 0.046 & -1.04 & 0.300 & 0.95 \\
\hline & Age & 0.087 & 0.003 & 28.97 & 0.000 & 1.09 \\
\hline & Educational level & & & & & \\
\hline & Low & 1.00 (ref) & & & & \\
\hline & Secondary & 0.086 & 0.057 & 1.50 & 0.133 & 1.09 \\
\hline & High & 0.103 & 0.073 & 1.42 & 0.157 & 1.11 \\
\hline & Unknown & -0.142 & 0.074 & -1.92 & 0.055 & 0.87 \\
\hline & Main diagnosis & & & & & \\
\hline & Mental & 1.00 (ref) & & & & \\
\hline & Musculoskeletal & -0.254 & 0.112 & -2.27 & 0.023 & 0.78 \\
\hline & Nervous system & -0.102 & 0.127 & -0.80 & 0.422 & 0.90 \\
\hline & Cardiovascular & -0.035 & 0.122 & -0.29 & 0.772 & 0.97 \\
\hline & Cancer & 0.371 & 0.127 & 2.92 & 0.004 & 1.45 \\
\hline & Other & 0.193 & 0.118 & 1.64 & 0.101 & 1.21 \\
\hline & Comorbidity & & & & & \\
\hline & Single mental disorder & 1.00 (ref) & & & & \\
\hline & Multiple mental disorders & 0.073 & 0.117 & 0.62 & 0.535 & 1.08 \\
\hline & Single physical disorder & 0.295 & 0.134 & 2.20 & 0.028 & 1.34 \\
\hline & Multiple physical disorders & 0.195 & 0.135 & 1.44 & 0.150 & 1.21 \\
\hline & Mental and physical & -0.016 & 0.104 & -0.15 & 0.880 & 0.98 \\
\hline
\end{tabular}

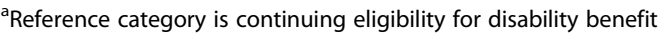

\section{Abbreviations}

CAS: Dutch Classification of Occupational Health and Social Insurance; ICD-

10: International Statistical Classification of Disease and Related Health Problems;

IP: Insurance physician; SSI: Social Security Institute; WIA: Dutch Work and Income Act

\section{Acknowledgements}

Not applicable.

\section{Funding}

This study is financially supported by the Dutch Social Security Institute. The funding organization had no further role in analysis and interpretation of data, in the writing of the paper and in the decision to submit the paper for publication.

\section{Availability of data and materials}

The dataset supporting the conclusions of this study is available through correspondence with the corresponding author.

\section{Authors' contributions}

All authors contributed to the writing and revision of the manuscript. IL was primarily responsible for the data collection, analyses and draft of the manuscript. MHA and HJvR were responsible for overseeing the analyses and supervising the first drafts of the manuscripts. AJvdB and JRA were mainly involved in formulating the research questions and interpretation of the findings. All authors read and approved the final manuscript.
Ethics approval and consent to participate

We received permission from the SSI to use their registration data for this study.

\section{Consent for publication}

Not applicable.

\section{Competing interests}

IL and HJvR are employed at the Dutch Social Security Institute. AJvdB and JRA are shareholder of VU University Medical Center spin-off company Evalua Nederland BV. JRA holds a chair in Insurance Medicine on behalf of the Dutch Institute for Employee Benefit Schemes.

\section{Publisher's Note}

Springer Nature remains neutral with regard to jurisdictional claims in published maps and institutional affiliations.

\section{Author details}

'Department of Public and Occupational Health, Amsterdam Public Health Research Institute, VU University Medical Center, Van der Boechorststraat 7, 1081, BT, Amsterdam, The Netherlands. ${ }^{2}$ Dutch Institute of Employee Benefit Schemes (UM), Amsterdam, The Netherlands. ${ }^{3}$ Research Center for Insurance Medicine, AMC-UMCG-VUmc, Amsterdam, The Netherlands. 
Received: 26 April 2017 Accepted: 11 January 2018

Published online: 18 January 2018

\section{References}

1. OECD. Sickness, Disability and Work: Breaking the Barriers: A Synthesis of Findings across OECD Countries. OECD Publishing. 2010. doi:https://doi.org/ 10.1787/9789264088856-en

2. Norström F, Virtanen P, Hammarström A, Gustafsson PE, Janlert U. How does unemployment affect self-assessed health? A systematic review focusing on subgroup effects. BMC Public Health. 2014;14(1310)

3. Backhans MC, Hemmingsson T. Unemployment and mental health-who is (not) affected? Eur J Pub Health. 2011;22:429-33.

4. Milner A, LaMontagne AD, Aitken Z, Bentley R, Kavanagh AM. Employment status and mental health among persons with and without a disability: evidence from an Australian cohort study. J Epidemiol Community Health. 2014:68:1064-71.

5. OECD. Sickness and Disability Schemes in the Netherlands. http://www. oecd.org/social/soc/41429917.pdf. Accessed 21 Feb 2017.

6. Steenstra IA, Knol DL, Bongers PM, Anema JR, van Mechelen W, de Vet HC What works best for whom?: an exploratory, subgroup analysis in a randomized, controlled trial on the effectiveness of a workplace intervention in low back pain patients on return to work. Spine. 2009:34:1243-9.

7. Brouwer S, Reneman MF, Bültmann U, van der Klink JJL, Groothoff JW. A prospective study of return to work across health conditions: perceived work attitude, self-efficacy and perceived social support. J Occup Rehabil. 2010;20:104-12.

8. Mittendorfer-Rutz E, Härkänen T, Tiihonen J, Haukka J. Association of sociodemographic factors, sick-leave and health care patterns with the risk of being granted a disability pension among psychiatric outpatients with depression. PLoS One. 2014;9:e99869.

9. Lagerveld SE, Bültmann U, Franche RL, Van Dijk FJH, Vlasveld MC, Van der Feltz-Cornelis CM, Nieuwenhuijsen K. Factors associated with work participation and work functioning in depressed workers: a systematic review. J Occup Rehabil. 2010:20:275-92.

10. Ervasti J, Vahtera J, Pentti J, Oksanen T, Ahola K, Kivimäki M, Virtanen M. Depression-related work disability: socioeconomic inequalities in onset, duration and recurrence. PLoS One. 2013;8:e79855.

11. Van Muijen P, Duijts SF, Bonefaas-Groenewoud K, van der Beek AJ, Anema $J R$. Factors associated with work disability in employed cancer survivors at 24-month sick leave. BMC Cancer. 2014;14(236)

12. EJ MK, Bosse MJ, Kellam JF, Pollak AN, Webb LX, Swiontkowski MF, MP MA Early predictors of long-term work disability after major limb trauma. Trauma. 2006;61:688-94.

13. Natvig B, Eriksen W, Bruusgaard D. Low back pain as a predictor of longterm work disability. Scand J Public Health. 2002;30:288-92.

14. World Health Organization: International Classification of Diseases. 2016 http://www.who.int/classifications/icd/en/. Accesses 6 Feb 2017.

15. Payne S, Doyal L. Older women, work and health. Occup Med (Lond). 2010; 60:172-7.

16. Najati G Jr, Lee S, McCann D. Conditions Of work and employment for older workers in industrialized countries: understanding the issues. No. 15. International labour Organization. 2006;

17. Dixon S. Implications Of population ageing for the labour market. Labour Market Trends. 2003;3:67-76.

18. OECD Sick on the Job? Myths and Realities about Mental Health and Work. OECD Publishing. 2012. doi:https://doi.org/10.1787/9789264124523-en.

19. Olfson M, Druss BG, Marcus SC. Trends in mental health care among children and adolescents. N Engl J Med. 2015;372:2029-38.

20. Twenge JM. Time period and birth cohort differences in depressive symptoms in the U.S., 1982-2013. Soc Indic Res. 2015;121:437-54.

21. Alonso J, Angermeyer MC, Bernert S, Bruffaerts R, Brugha TS, Bryson H, Haro JM. Prevalence of mental disorders in Europe: results from the European study of the epidemiology of mental disorders (ESEMeD) project. Acta Psychiatr Scand. 2004;109:21-7.

22. MFA VH, Joling Cl, Heymans MW, JWR T, CAM R. Mental health symptoms identify workers at risk of long-term sickness absence due to mental disorders: prospective cohort study with 2-year follow-up. BMC Public Health. 2015;15:1235.

23. Kinge JM, Knudsen AK, Skirbekk V, Vollset SE. Musculoskeletal disorders in Norway: prevalence of chronicity and use of primary and specialist health care services. BMC Musculoskelet Disord. 2015;16(75)
24. Woolf AD, Pfleger B. Burden Of major musculoskeletal conditions. Bull World Health Organ. 2013:81:646-56.

25. Ervasti J, Kivimäki M, Pentti J, Salo P, Oksanen T, Vahtera J, Virtanen M. Healthand work-related predictors of work disability among employees with a cardiometabolic disease—a cohort study. J Psychosom Res. 2016;82:41-7.

26. Sorvaniemia M, Heleniusb $H$, Salokangas RKR. Factors associated with being granted a pension among psychiatric outpatients with major depression. J Affect Disord. 2003;75:43-8.

27. Cornelius LR, Van der Klink JJL, Groothoff JW, Brouwer S. Prognostic factors of long term disability due to mental disorders: a systematic review. J Occup Rehabil. 2011:21:259-74.

28. Dutch Social Security Agency. Annual statistical report on the Security Disability Insurance Program. http://www.uwv.nl/overuwv/lmages/ UWV\%20Kennisverslag\%202015-2.pdf. Accessed 6 Feb 2017.

\section{Submit your next manuscript to BioMed Central and we will help you at every step:}

- We accept pre-submission inquiries

- Our selector tool helps you to find the most relevant journal

- We provide round the clock customer support

- Convenient online submission

- Thorough peer review

- Inclusion in PubMed and all major indexing services

- Maximum visibility for your research

Submit your manuscript at www.biomedcentral.com/submit 